\title{
"PLANTÃO DA CIDADE": um estudo da participação política local e constituição de subjetividades por meio do Facebook
}

"PLANTÃO DA CIDADE": a study of local political participation and the constitution of subjectivities through Facebook

"PLANTÃO DA CIDADE": Un estudio de la participación política local y la constitución de subjetividades a través de Facebook

\section{Hila Rodrigues}

Doutorado em Ciências Sociais pela Universidade Federal de Minas Gerais (UFMG). Professora do Programa de Pós-Graduação em Comunicação da Universidade Federal de Ouro Preto (UFOP). hila.rodrigues@ufop.edu.br.

0000-0001-9277-8757

\section{Isabela Melo}

Mestre em Comunicação pela Universidade Federal de Ouro Preto (UFOP). melo.isabela02@gmail.com.

\section{0-0001-9371-0623}

Correspondência: Instituto de Ciências Sociais Aplicadas (ICSA). Rua do Catete, 166 - Centro. CEP 35420-000 - Mariana, MG, Brasil.

Recebido em: 12.10.2020.

Aceito em: 20.11.2020.

Publicado em: 01.01.2021.

\begin{abstract}
RESUMO:
O objetivo desse artigo é discutir a participação política dos cidadãos mediada pelas tecnologias de comunicação. Procuramos compreender os potenciais cenários e meios para a promoção da participação cidadã no universo do poder público. A investigação se deu a partir da observação de um espaço específico no Facebook: o grupo Plantão da Cidade, criado no município de Ouro Preto para viabilizar discussões de cunho político. O exame proposto evidencia as possibilidades oferecidas pelo ambiente online para assegurar a participação política do cidadão comum nas decisões da gestão municipal e a mobilização de ações comunitárias locais.

PALAVRAS-CHAVES:

Cidadania.

Deliberação. Facebook. Participação política. Redes sociais.
\end{abstract}

\section{Introdução}

As tecnologias de comunicação que dão formato e dinâmica às redes sociais online, tais como o Facebook, Twitter e Instagram, oferecem muitas possibilidades de interação em numerosos lugares do mundo. No âmbito das práticas sociais, essas redes permitem e estimulam a emergência de novos modos de relacionamento e de produção de sentido, além de estabelecer padrões renovados de sociabilidade. Além disso, são plataformas que se revelam cada vez mais úteis no campo da política - tanto para as instituições públicas quanto para o cidadão comum.

Parte expressiva dos estudos sobre participação política e internet indicam que o ambiente digital abre caminhos efetivos para a comunicação entre os cidadãos e o poder público. Estudiosos atentos a esse campo de investigação - como Rousiley Maia (2008), Wilson Gomes (2005), Rodrigo Carreiro (2017) e Samuel Barros (2019) - procuram discutir, sob variadas perspectivas e objetos empíricos, os efeitos sociais desse tipo de comunicação. Trata-se de um esforço de compreensão das potencialidades, mas também das limitações desses processos de interação, de trocas e de conversação. 
Em diálogo com essa literatura, esse artigo se orienta por reflexões pontuais sobre a sociedade, sobre a política e sobre a comunicação. Voltamos nosso olhar para um cenário regional e, a partir desse lugar, analisamos um grupo específico no Facebook, chamado Plantão da Cidade Ouro Preto. Como o nome indica, o grupo é composto por cidadãos que vivem em Ouro Preto - município mineiro situado a $96 \mathrm{~km}$ da capital, localizada em uma das principais áreas do ciclo do ouro no Brasil e primeiro sítio brasileiro considerado Patrimônio Mundial pela UNESCO. O grupo recorre a essa plataforma para debater temas de cunho sociopolítico e cultural que envolvam interesses em comum. Nesse espaço, os participantes ganham visibilidade e, não raras vezes, influenciam as decisões tomadas por parte das autoridades públicas que compõem a esfera governamental local.

A partir desse quadro, o objetivo desse estudo é compreender como esses cidadãos se apropriam do Facebook e como esses modos de interação, de conversação e produção de sentido impactam o comportamento e as ações do poder público municipal. A metodologia adotada se baseia na análise dos processos de trocas argumentativas online proposta por Ângela Marques (2011), inspirada nos estudos de Stromer-Galley (2005), Graham (2008) e Kies (2010). Esse percurso metodológico recorre especialmente à codificação das postagens selecionadas - considerando a dinâmica do debate e as características específicas do grupo em análise -, bem como aos recursos e às ferramentas do ambiente digital acionados pelos participantes.

Tendo em mente que o exercício da política não se esgota nas disputas partidárias e eleitorais - nem se atém tão somente aos espaços institucionais -, a ideia é mirar esses ambientes online como espaço capaz de proporcionar debates políticos importantes propostos (e acolhidos) pelos moradores de Ouro Preto. Ao atrair cidadãos interessados em expor questões de interesse coletivo, o Plantão da Cidade abre caminhos curiosos para o debate de temas complexos envolvendo as políticas sociais implementadas pelo setor público municipal e o comportamento da própria população diante de decisões tomadas nas esferas institucionais.

\section{Participação política online}

As tecnologias de comunicação influenciam a forma como os indivíduos assimilam as realidades que experimentam, mas não apenas. Elas influenciam, principalmente, o modo como as pessoas se posicionam em relação à maneira como as autoridades públicas gerenciam suas vidas. Esse é um fenômeno especialmente evidenciado pelos os estudiosos que se dedicaram à observação dos processos de conversação política nos ambientes digitais. Esse tipo de participação cidadã - que, 
exatamente por partir da conversação, permite um aumento da visibilidade dos temas colocados e difusão de conteúdos variados - contribui para um alargamento dos pontos de vista que atravessam o dia a dia dos cidadãos e também das autoridades públicas. Ao mesmo tempo, concorre para a ressignificação das experiências cotidianas.

Tudo isso se descortina nos posicionamentos adotados e nas ideias preconizadas pelos sujeitos participantes das conversações. Esses são atos de participação política passíveis de serem tomados, nessa perspectiva, como "atividades sociais desenhadas, pelo estado ou pela sociedade civil, com o intuito de que os cidadãos interfiram no processo de tomada de decisão política." (MATOS; BARROS, CARREIRO, 2019, p.204). É também sob esse aspecto que Venício Lima (2017) considera oportunas as tecnologias de comunicação proporcionadas aos cidadãos nas últimas décadas. Em seu trabalho de releitura do conceito de "cultura do silêncio" construído por Paulo Freire (1921-1997), ele observa que, embora o acesso à internet ainda não seja garantido a todas as parcelas da população brasileira, as redes sociais são hoje canais que facilitam de forma impressionante a propagação da voz do cidadão comum e também da sua visão sobre as decisões e deliberações do poder público.

Trata-se de concepção similar à de Wilson Gomes (2008) ao se perguntar o que, afinal, pode fazer a internet pela participação política. Constata, nessa abordagem, que as características estruturais e circunstanciais dos meios de comunicação digital são capazes de assegurar esse tipo de participação e, a partir daí, contribuir para o fortalecimento dos regimes democráticos - em especial no contexto brasileiro, permeado por crise e queda da credibilidade dos representantes políticos. Para Gomes, a internet proporciona a superação dos limites de tempo e espaço para a participação política, além de certa comodidade e extensão do acesso.

No âmbito das instituições públicas - e em especial nos parlamentos - a internet ocasionou e impulsionou, nos últimos anos, a emergência de variadas iniciativas de democracia digital ${ }^{1}$. Fazem parte desse universo os fóruns, os aplicativos institucionais, as consultas públicas e a produção de matérias legislativas com o auxílio de tecnologias digitais, além da utilização de ambientes online para processos de deliberação pública. Para Marques (2011) a deliberação deve ser compreendida, aqui, como atividade discursiva integrante de um processo social de comunicação. Não se restringe, assim, à troca de argumentos racionais ou a um momento único da decisão tomada. Nessa

\footnotetext{
${ }^{1}$ Por democracia digital, compreende-se o "emprego de tecnologias digitais de comunicação com o objetivo de corrigir, incrementar ou incorporar novos procedimentos ao processo político, no sentido de melhor atender a um ou mais princípios da democracia". (GOMES, 2011, p.27-28).
} 
perspectiva, revela-se então um processo comunicativo em que diferentes atores, a partir de seus respectivos discursos, estabelecem um diálogo tendo como objetivo a compreensão de um problema em comum em pauta. Nesse sentido, o movimento em direção ao outro envolve duas importantes dimensões do uso da linguagem: a afetiva e a reflexiva. A primeira está voltada para o jogo lúdico da socialização e a segunda para as questões e normas institucionalizadas de interesse coletivo. (MARQUES, 2011). Ambas estão especialmente presentes nas conversações políticas observadas nos ambientes online.

\section{Conversação política online como prática social}

No grupo de Facebook Plantão da Cidade Ouro Preto, a conversação política carrega fortemente essa dimensão afetiva cognitiva, caracterizada pelas expressões de emoção, por narrativas do cotidiano e por testemunhos que possuem, em comum, a marca de uma urgência: colocar em pauta temas de interesse da coletividade. Ângela Marques (2011) observa que esse tipo de conversação emerge no universo online sempre que indivíduos e grupos entendem que uma determinada questão "merece ser discutida de maneira coletiva, de modo a buscar um entendimento recíproco do problema em causa" (p. 20).

Importante observar, nesse ponto, que essa conversação, ainda que de cunho sociopolítico, está muito além de temas meramente partidários (ou que envolvam disputas eleitorais). Ela diz respeito principalmente às necessidades, interesses e sonhos de uma sociedade que circula e experimenta a vida em um determinado lugar, governado por determinadas forças políticas. É isso o que está presente no espaço online do grupo Plantão da Cidade Ouro Preto, ou seja, as particularidades que atravessam e desafiam o município, a vida de seus moradores e as lutas travadas naquele espaço. Segundo Maia et all (2016), compreender as especificidades de cada ambiente online de conversação política é compreender sua lógica e sua cultura - o que os estudiosos chamarão de semântica coletiva.

Esses são processos que se assemelham à maneira como os movimentos sociais - sejam quais forem - constroem, ao longo do tempo e através da interação de seus participantes, certa estrutura ideológica. A troca de opinião, o reconhecimento mútuo em relação a determinadas reivindicações, a solidariedade e as crenças compartilhadas fazem surgir uma identificação. Passa a existir um significado para o "nós" da ação coletiva. Nos ambientes online, esses fatores costumam avigorar os exercícios de cidadania e seus efeitos em meio à vida cotidiana - e não somente nos períodos eleitorais. 
Foi ao analisar os efeitos das tecnologias de comunicação nas rotinas dos movimentos sociais que Rousiley Maia (2008) observou, por exemplo, o surgimento de alguns fenômenos tais como um esforço de interpretação de interesses diversos, a formação de identidades coletivas, o ativismo político, os embates institucionais e a partilha de poder, entre outras dinâmicas. Isso mostra que processos deliberativos ampliados podem contribuir para a reprodução do sentimento de solidariedade, para a formação de vínculos basilares e para a constituição de identidades e de subjetividades coletivas. Para Marques e Maia (2008), o que o ambiente digital faz, nesse sentido, é possibilitar a ampliação dos encontros - o que impulsiona esses processos.

No contexto local - como é caso da cidade de Ouro Preto - a participação política se dá, em especial, através das trocas sociais, isto é, do compartilhamento de afetos por meio de testemunhos e narrativas pessoais, como é possível perceber no Plantão da Cidade. Os integrantes do grupo vivenciam os principais problemas do município e identificam com precisão aquilo que efetivamente interessa a população. Esse tipo de espaço, como acentuam Rosseto, Carreiro e Reis (2015), permite, de maneira geral, que qualquer cidadão tenha "uma noção geral da opinião coletiva sobre temas que estão na pauta", bem como "identificar perfis ou websites de causas políticas específicas em que é possível se engajar", além de comparar suas próprias opiniões com as de outras pessoas (p.4).

Não significa, evidentemente, que, ao alargar as possibilidades de participação política, a internet tenha constituído paraísos democráticos pautados pela igualdade, pela justiça, por princípios humanitários ou pela ética. As tecnologias de comunicação, sabemos, são propagadoras também de discursos antidemocráticos, preconceituosos e nefastos. E contribuem também para a desinformação. Bons exemplos amplamente registrados pela imprensa estão nas eleições presidenciais vencidas em 2016 por Donald Trump, nos Estados Unidos, e por Jair Bolsonaro em 2018, no Brasil - ambos beneficiados pela grande produção e circulação de fake news. As notícias falsas também influenciaram o referendo do Brexit, que permitiu, em janeiro de 2020, a saída formal do Reino Unido da União Euroéia. ${ }^{2}$

É partindo desse aspecto, aliás, que Wilson Gomes (2008) atenta para um detalhe importante nesse contexto: o de que, para entender a participação política dos cidadãos, é preciso afastar-se da retórica do que é positivo ou negativo. Essencial é compreender de que maneira essa participação pode estimular o cidadão a se envolver na vida política de sua cidade, estado ou país e, a partir daí, cultivar virtudes cívicas. Nesse sentido, o

\footnotetext{
${ }^{2}$ Ver https://piaui.folha.uol.com.br/lupa/2018/09/24/brasil-eua-brexit-noticias-falsas/. Acesso: 12 jun. 2020.
} 
que está claro - e já amplamente registrado pela literatura - é a importância dos processos que transformam questões de interesse coletivo em debates públicos, subsidiando a agenda e as decisões governamentais.

\section{"Plantão da Cidade Ouro Preto" - da visibilidade à dinâmica discursiva}

Refletir sobre as dinâmicas conversacionais presentes nas redes sociais e seus efeitos exige um olhar atento para a arquitetura discursiva dos espaços online. Nessa seção apresentaremos brevemente as especificidades do grupo Plantão da Cidade Ouro Preto, criado em 30 de abril do ano de 2012. A primeira mensagem postada pelo seu fundador explicava o papel a ser cumprido por aquele novo ambiente online da seguinte forma:

A ideia principal deste espaço é informar, comentar, questionar, justificar e integrar sobre temas do cotidiano de Ouro Preto, dando enfoque a tudo que acontece, o que falta acontecer ou o que demora a acontecer. O nome PLANTÃO sugere um canal sempre ligado a qualquer novidade, que contempla, além dos contextos, as imagens de registros dos fatos. ${ }^{3}$

O grupo ingressou no ano de 2020 com 14.558 mil membros e três moderadores. As postagens se apresentam na forma de trocas discursivas sobre temas considerados substanciais para os cidadãos ouro-pretanos, principalmente no que diz respeito à saúde, educação, manutenção de espaços públicos, transparência e prestação de contas por parte da gestão pública. Também é possível encontrar certas narrativas do cotidiano, conteúdos reflexivos, além de protestos e convocações. Essa dinâmica se dá por meio de textos, vídeos, fotos e memes, principalmente. O elemento mais curioso desse ambiente é o "resumo"4 das reuniões ordinárias da Câmara Municipal de Ouro Preto postado semanalmente, algo bastante peculiar no âmbito da participação política cidadã. Há, ainda, comentários acerca de discursos e ações que revelam posturas de autopromoção por parte dos parlamentares e da própria Prefeitura, bem como informações referentes à agenda mensal de eventos culturais e religiosos da região.

As postagens dos cidadãos no grupo proporcionam o compartilhamento de informações importantes sobre a cidade e sua rotina - nas ruas e nas instituições -, além de diálogos que contribuem para a compreensão e avaliação dos problemas locais. Os

\footnotetext{
${ }^{3}$ Grupo Plantão da Cidade Ouro Preto. Disponível em: <https://ptbr.facebook.com/groups/228600653911959/>. Acesso em: 30 set. 2019.

4Uma cidadã ouro-pretana realiza, semanalmente, uma síntese das reuniões ordinárias da Câmara Municipal de Ouro Preto. Apresenta, de forma subjetiva e dinâmica, o relato das principais ideias discutidas a partir de requerimentos e representações apresentados, e também das indicações em pauta. O resumo dá uma ideia da situação política vivenciada pelo município. O texto trata dos temas presentes nas pautas de discussão e votação da Câmara, com ênfase às questões básicas de interesse popular - em especial nas áreas de saúde, educação, segurança, prestação de conta e limpeza urbana.
} 
conteúdos costumam pautar e, por vezes, mobilizar os atores políticos responsáveis pela condução de certos processos relativos à administração local. Muitas demandas dos moradores ganham visibilidade - demandas que, de outra maneira, poderiam ser ignoradas. Desta forma, as postagens não possuem o objetivo de "informar" no sentido jornalístico, mas, efetivamente, experimentar uma prática dialógica, em que "a conversação entre muitos cria pensamento" (BENTES, 2015, p. 12).

Assim como ocorre em espaços off-line, os cidadãos que frequentam essa plataforma desenvolvem muitas vezes sentimentos de pertencimento, laços afetivos e de proximidade. Nesse sentido, existe uma ampliação do círculo social (BARROS; CARREIRO, 2015). O Plantão da Cidade apresenta essas particularidades que proporcionam o engajamento dos participantes em debates de cunho sociopolítico que reverberam nos âmbitos institucionais do município de Ouro Preto. As conversas travadas entre os integrantes afetam em especial a Câmara dos Vereadores e a Prefeitura. Por mais de uma vez, temas levantados pelo grupo pautaram a discussão dos parlamentares em plenário, por exemplo.

Fato é que os integrantes desse grupo reservam parte de sua rotina diária para só tratar de questões os afetam como moradores de Ouro Preto. Esse processo de troca, em geral inspirado em testemunhos pessoais, é marcado por reenquadramentos interpretativos de situações e acontecimentos que interferem nos cenários e no cotidiano da cidade e de sua população. A análise empreendida a partir dos diálogos observados evidencia aspectos importantes nesse sentido, como se verá a seguir.

\section{Análise e indicativos}

O percurso investigativo definido para descortinar a maneira como os cidadãos ouro-pretanos se apropriam do grupo Plantão da cidade - ancorados à discussão dos temas ali pautados, centrados principalmente nas políticas públicas voltadas para o município - foi divido em algumas etapas. A primeira se deu a partir da navegação exploratória, com a finalidade de identificar as particularidades que atravessam as publicações e as dinâmicas conversacionais naquele ambiente. O corpus analítico contemplou, então, três postagens selecionadas a partir do expressivo potencial discursivo que geraram durante o período da investigação. Juntas, essas postagens renderam um total de 219 comentários examinados. São elas: (1) a desconstrução, por um guarda municipal de Ouro Preto, de um tapete de serragem que, no ano de 2019, durante as celebrações da Semana Santa, homenageava a vereadora Marielle Franco, assassinada a tiros em 14 de março de 2018 no Estácio, região central do Rio de Janeiro; (2) Conflitos entre moradores e parlamentares do município em razão da política de 


\section{Qrevisto Observatório}

terceirização do setor de saúde; (3) a denúncia de abandono, por parte do poder público municipal, de um complexo esportivo conhecido como "Campo do bairro Água Limpa" .

\begin{tabular}{|l|l|l|l|l|l|l|}
\hline POSTAGEM & TEMA & DATA & IMAGEM & CURTIDAS & COMENTÁRIOS & COMPATILHAMENTOS \\
\hline $\mathbf{1}$ & $\begin{array}{c}\text { Tapetes da } \\
\text { semana santa }\end{array}$ & $\begin{array}{l}21 \text { abril } \\
2019\end{array}$ & Não & 62 & 63 & 4 \\
\hline $\mathbf{2}$ & $\begin{array}{c}\text { Terceirização } \\
\text { da saúde de } \\
\text { Ouro Preto- } \\
\text { MG }\end{array}$ & $\begin{array}{l}26 \text { abril } \\
2018\end{array}$ & $\begin{array}{l}\text { Sim } \\
\text { (fotografia) }\end{array}$ & 42 & 99 & 9 \\
\hline $\mathbf{3}$ & $\begin{array}{c}\text { Campo do } \\
\text { Água Limpa }\end{array}$ & $\begin{array}{l}30 \\
\text { setembro } \\
2019\end{array}$ & $\begin{array}{l}\text { Sim (vídeo } \\
\text { do vestiário } \\
\text { do campo }\end{array}$ & 42 & 57 & \\
\hline
\end{tabular}

Fonte: Pesquisa Plantão da Cidade Ouro Preto - Quadro analítico

A etapa seguinte constituiu-se do exame desses comentários, considerando, sobretudo, as dinâmicas discursivas e os recursos utilizados pelos participantes durante a conversação. Nesse momento, estabelecemos as categorias de análise definidas em conformidade com a proposta teórico-metodológica de Marques (2011) e de Carreiro (2017). O quadro abaixo organiza o processo analítico e foi utilizado para a verificação dos comentários nas três postagens selecionadas e acima descritas.

CATEGORIAS

FORMA

APRESENTAR

COMENTÁRIO

\section{COMENTÁRIO}

\section{DESCRIÇÃO}

DE Tem como objetivo definir a

O maneira que o participante se apresenta na discussão.

DO Essa categoria busca entender o papel do comentário na discussão diante da postagem inicial ou dos argumentos contidos na conversa.

\section{OPERADORES}

\section{RELACIONADOS}

-Declaração/afirmação

-Ponto de vista oposto

-Esclarecimento

-Nova abordagem

-Questionamento

-Neutro

-Novo ponto de vista

-Apoio

-Contra 


\begin{tabular}{|c|c|c|}
\hline $\begin{array}{l}\text { RECURSOS } \\
\text { ARGUMENTATIVOS }\end{array}$ & $\begin{array}{l}\text { Essa categoria procura } \\
\text { conhecer os elementos que } \\
\text { reforçam a argumentação e } \\
\text { complementam o comentário. }\end{array}$ & $\begin{array}{l}\text {-Fonte de informação } \\
\text {-Testemunho pessoal } \\
\text {-Nenhum } \\
\text {-Ironia } \\
\text {-Humor }\end{array}$ \\
\hline $\begin{array}{l}\text { RECURSOS TÉCNICOS } \\
\text { UTILIZADOS }\end{array}$ & $\begin{array}{l}\text { Refere-se à utilização de } \\
\text { elementos disponíveis na } \\
\text { plataforma no grupo Plantão } \\
\text { da Cidade no Facebook. }\end{array}$ & $\begin{array}{l}\text { - Texto } \\
\text {-Imagem } \\
\text {-Meme } \\
\text {-Vídeo } \\
\text {-Link }\end{array}$ \\
\hline $\begin{array}{l}\text { RELAÇÃO AO PODER } \\
\text { PÚBLICO MUNICIPAL }\end{array}$ & $\begin{array}{l}\text { Diz respeito à finalidade do } \\
\text { comentário em relação ao } \\
\text { poder público municipal. }\end{array}$ & $\begin{array}{l}\text {-Positivo } \\
\text {-Negativo } \\
\text {-Neutro (não há relação ao } \\
\text { poder público municipal) }\end{array}$ \\
\hline
\end{tabular}

Fonte: Pesquisa Plantão da Cidade Ouro Preto - Quadro analítico

Com as categorias definidas, partiu-se para a próxima etapa de pesquisa, que consistiu na leitura atenta de todos os comentários, considerando as dinâmicas do debate em pauta e os recursos utilizados pelos participantes. Ao examinar as conversações no Plantão da Cidade a partir das categorias trabalhadas, a ideia foi identificar as especificidades do grupo, a forma como os cidadãos se articulam na discussão com os outros, o funcionamento geral do debate, os recursos empregados para a argumentação e o posicionamento do cidadão perante a atuação do poder público municipal do tema proposto em cada postagem.

A análise de todo o material organizado proporciona uma visão ampliada e curiosa das particularidades da conversação política no Plantão da Cidade Ouro Preto. Os dados - que, no formato abaixo, podem ser comparados entre si - evidenciam as maneiras como os cidadãos que participam do grupo se apropriam desse espaço a fim de publicar, ler e reagir às postagens analisadas. 
Figura 1 - Gráfico - Forma de apresentar o comentário.

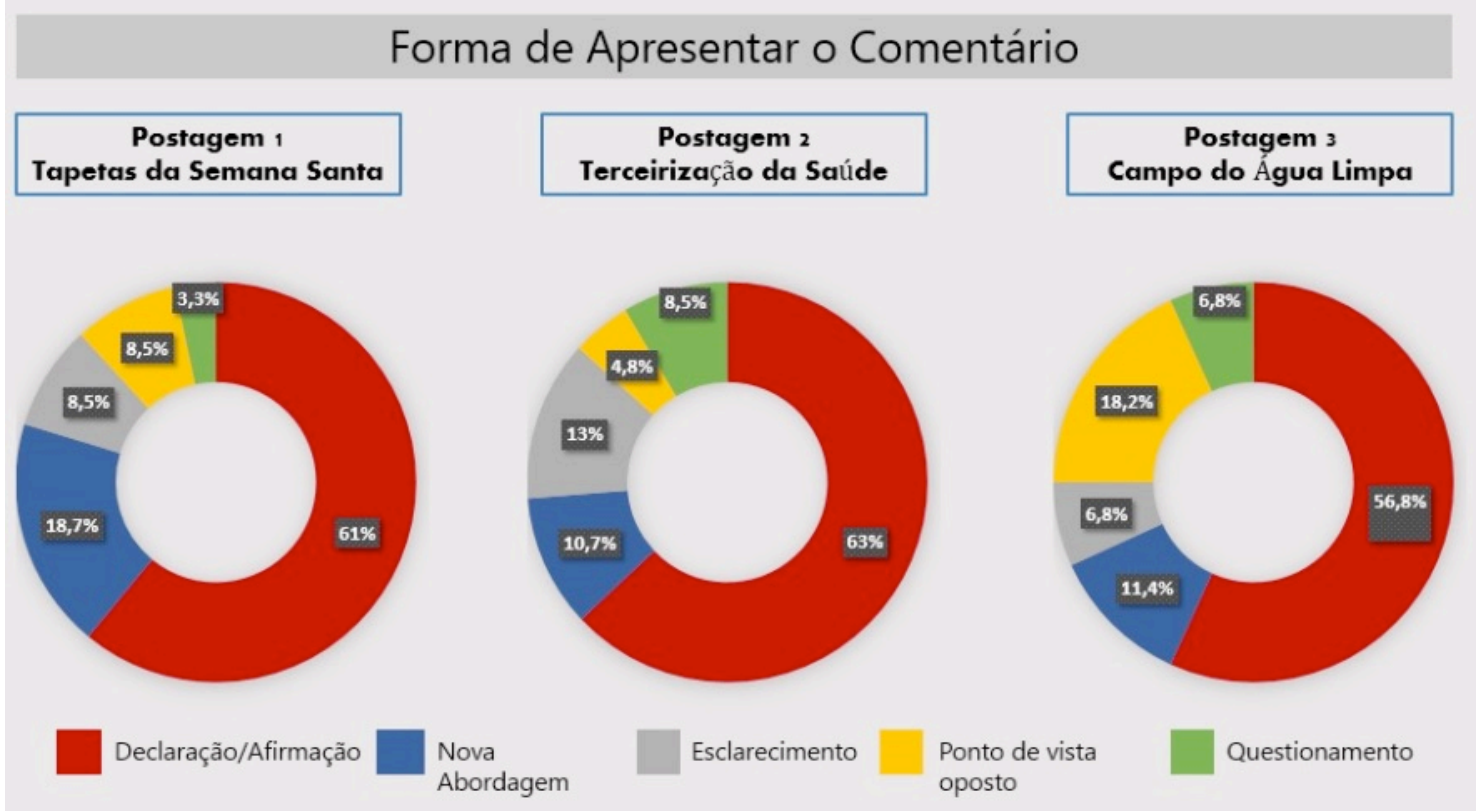

Fonte: Dados da Pesquisa, 2019.

Figura 2 - Gráfico - Objetivo do comentário.

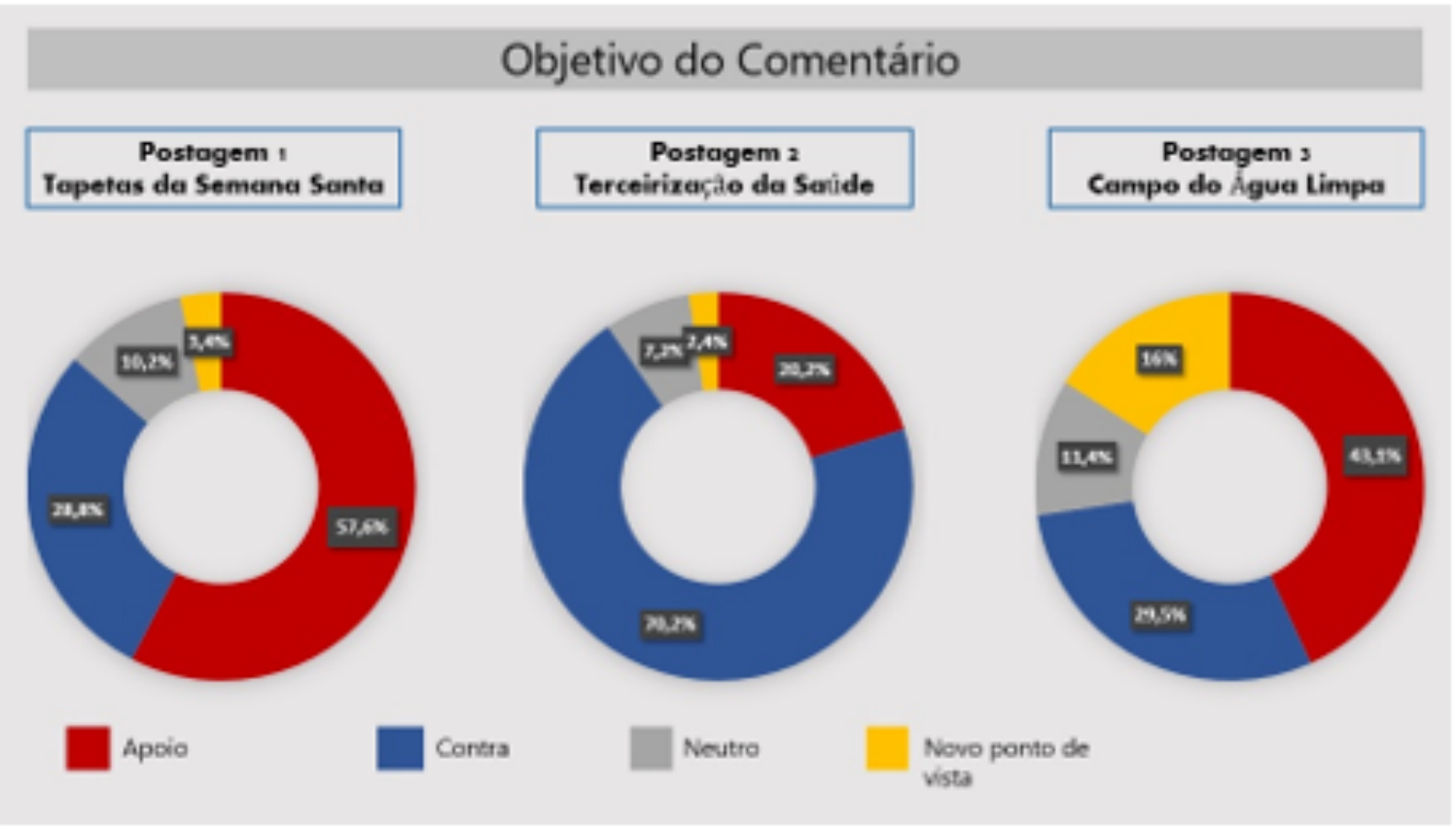

Fonte: Dados da Pesquisa, 2019. 
Fiqura 3 - Gráfico - Recursos Arqumentativos.

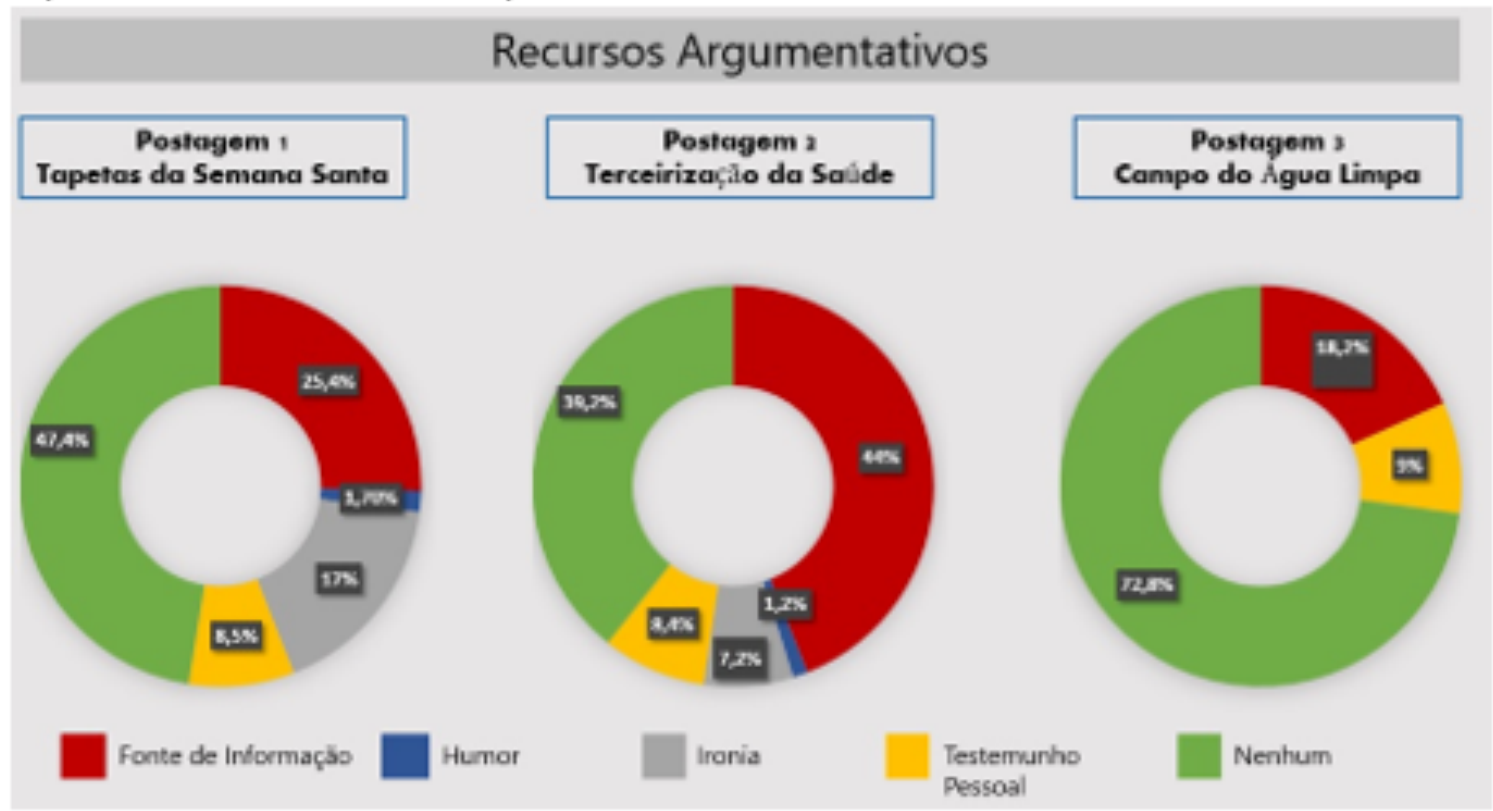

Fonte: Dados da Pesquisa, 2019.

Fiqura 4 - Gráfico - Recursos Técnicos Utilizados

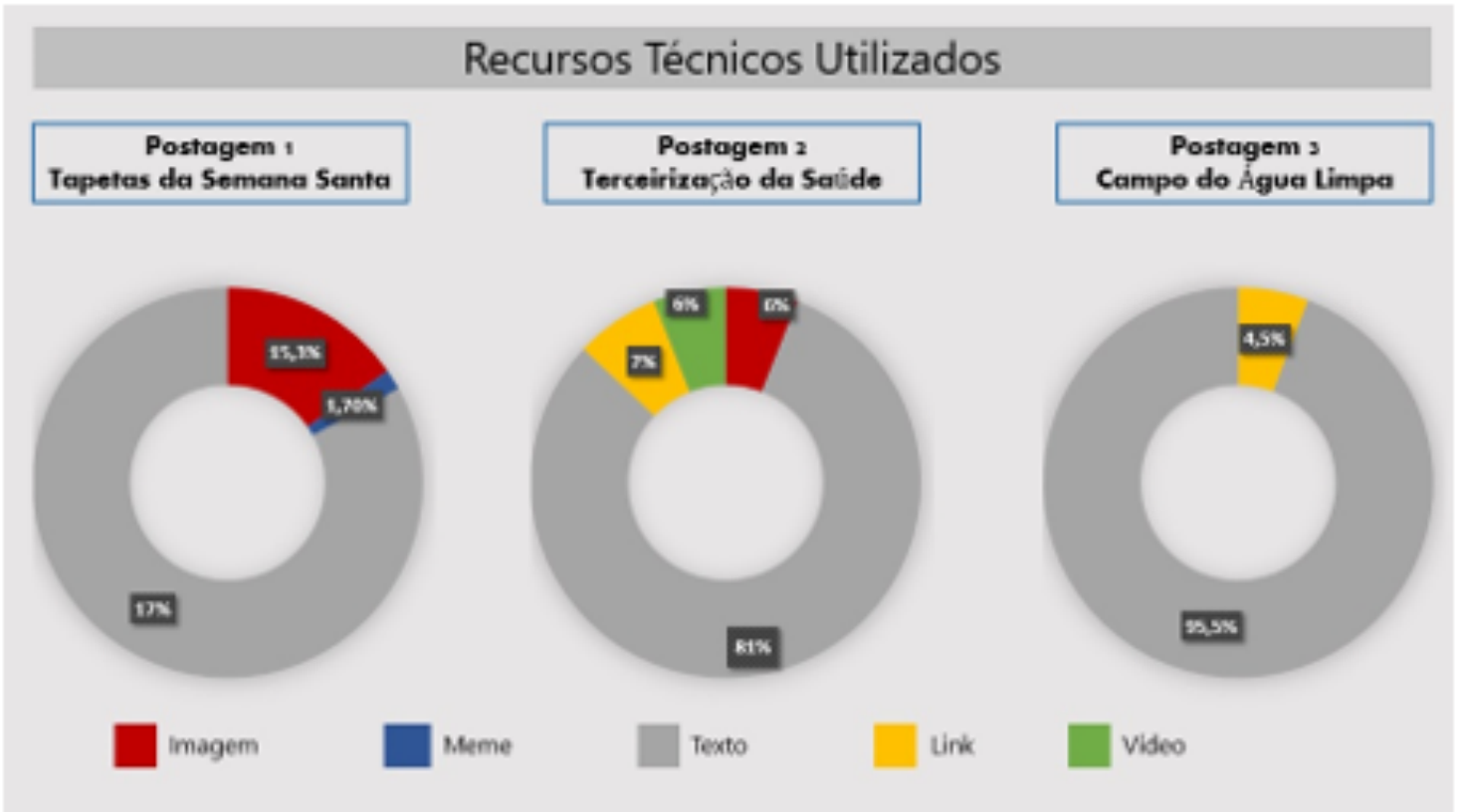

Fonte: Dados da Pesquisar 2019. 
Fiqura 5 - Gráfico - Relaçầo ao Poder Público Municipal

Relação ao Poder Público Municipal

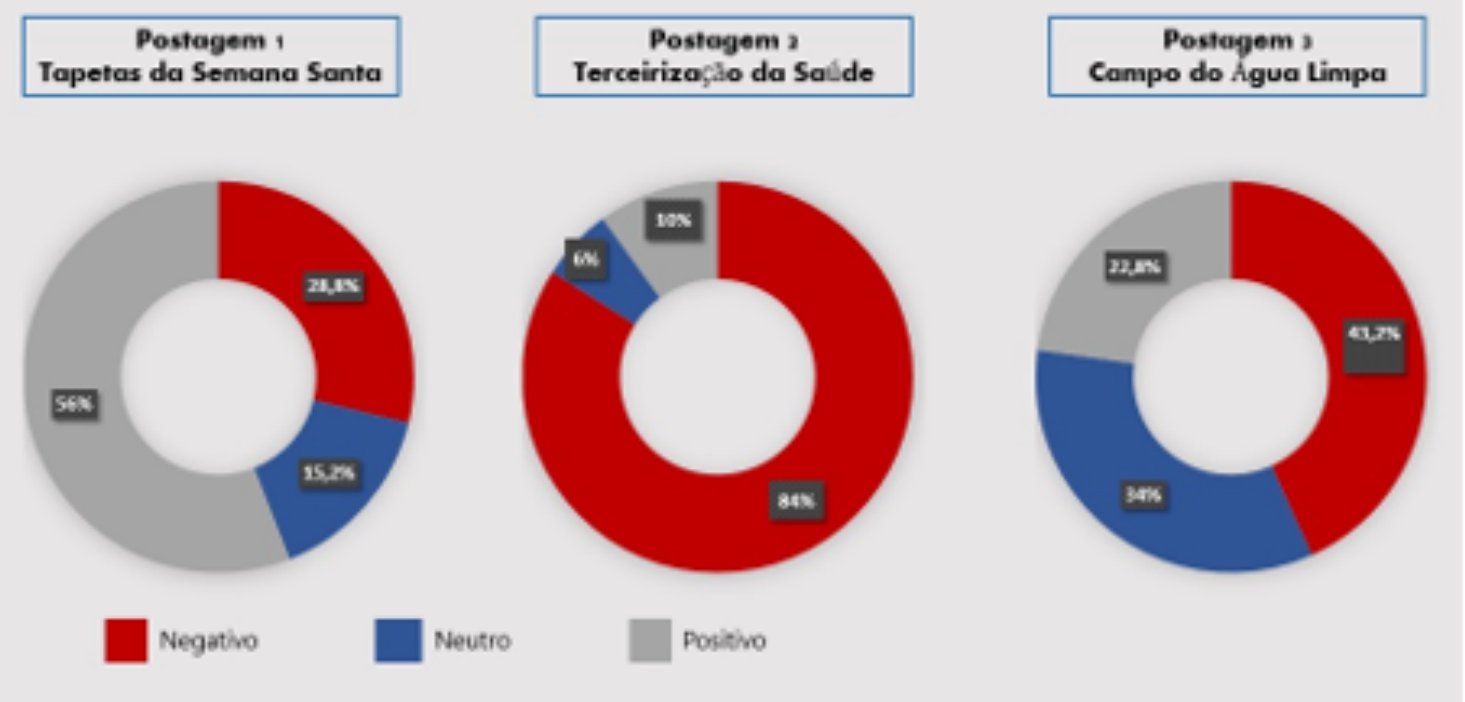

Fonte: Dados da Pesquisa, 2019.

Nos gráficos extraídos a partir da codificação dos comentários, é possível perceber como os temas afeitos à política ouro-pretana abordados nesse espaço do Facebook são valorizados na condição de problemas fundados nas demandas por políticas públicas (caso da terceirização da saúde e do campo esportivo), e nas questões atravessadas pelas nuances da cultura local, fortemente atravessada pelo grande poder e influência ainda exercidos pela Igreja Católica no município (caso do tapete que homageia Marielle Franco). De qualquer maneira, a discussão emerge, em larga medida, descolada das disputas meramente partidárias. Os interesses mais pragmáticos da coletividade - e a vivência das tradições culturais, especialmente as de cunho religioso emergem acima dos interesses ideológicos, embora estes estejam presentes e possam ser observados no campo das subjetividades próprias das dinâmicas discursivas.

Outro aspecto revelado está na concretização dessa concepção da deliberação como um processo iniciado a partir da assimilação das questões em pauta - e que está além da tomada de decisão em si. Ela emerge, nesse ambiente online, como um processo social de comunicação que busca, principalmente, a elucidação dos temas elencados para o debate. Aqui, a deliberação desponta em sua perspectiva sociológica, e não pelo caráter normativo. O Plantão da Cidade assegura, assim, oportunidades reais de debates e de ações coletivas, em especial na esfera pública municipal, onde a relação entre o cidadão e o poder governamental revela-se mais próxima. 


\section{Considerações finais}

Esse olhar empírico sobre um grupo de Facebook que influencia os moradores, os vereadores e as autoridades públicas do município mineiro de Ouro Preto é uma tentativa de alargar o campo dos debates acerca da conversação política em ambientes online. Permite que pensemos essas plataformas como um importante lugar para a observação das dinâmicas discursivas que a internet proporciona, mas também como espaços de debates potentes para influenciar as ações daqueles que representam os cidadãos na esfera governamental. Em especial nas cidades menores. Refletir sobre a conversação política a partir delas é apenas uma das maneiras de vislumbrar o mundo e seus diálogos - um exercício cada vez mais desafiador.

Mas pensar a influência dessas plataformas no cotidiano do cidadão comum, nas pequenas ou nas grandes localidades, não basta. É preciso nos atermos também aos efeitos dessa influência na vida das pessoas em diferentes sociedades espalhadas pelos continentes. E é importante mirar, sobretudo, na maneira como as conversações observadas no universo online proporcionam cada vez mais essa experiência dupla afetiva e política.

São questões que ganham contornos renovados em momentos de enfrentamento como esse, marcado por pandemias, discursos de ódio e regimes autoritários. Nesses cenários, as plataformas online são acessadas não somente para o compartilhamento de informações, mas também - e principalmente - para a disseminação de notícias falsas e discursos preconceituosos. O segundo milênio se desenrola em meio a uma das maiores crises enfrentadas pela humanidade, sujeita a cenários tenebrosos em função da morte de milhares pessoas - se não pelo adoecimento, pela violência. Especialmente as parcelas mais pobres das populações. Nesse contexto, refletir sobre o campo da conversação política nos ambientes digitais mas também sobre as possibilidades reais de participação política do cidadão comum nesses espaços - pode estimular outra importante discussão, desta vez inspirada em dois movimentos que consideramos fundamentais para a humanidade: os deslocamentos possíveis do poder na esfera política, e os deslocamentos latentes do poder nas sociedades.

\section{Referências}

ALMADA, Maria Paula; CARREIRO, Rodrigo; BARROS, Samuel; GOMES, Wilson.

Democracia digital no Brasil: obrigação legal, pressão política e viabilidade tecnológica. Matrizes, São Paulo, v. 13, n.3, p- 161-181, set/dez.2019. 
BARROS, Samuel; CARREIRO, Rodrigo. A discussão pública e as redes sociais online: o comentário de notícias no Facebook. Revista Fronteiras - Estudos Midiáticos, São Leopoldo, v. 17, n. 2, p. 174-185, 2015.

BENTES, Ivana. Mídia-Multidão: estéticas da comunicação e biopolíticas. Rio de Janeiro: Mauad X, 2015.

CARREIRO, Rodrigo. A Discussão Política Em Rede: Um Estudo Sobre a Divergência Política no Facebook. 2017. 246 f. Tese (Doutorado em Comunicação e Cultura Contemporâneas) - Universidade Federal da Bahia, Salvador, 2017.

CHAGAS, Viktor et ali. A Política dos Memes e os Memes da Política: proposta metodológica de análise de conteúdo de memes dos debates eleitorais de 2014. Intexto. N. 38, 2017.

GOMES, W. Da discussão à visibilidade. In: GOMES, W.; MAIA, R. Comunicação e democracia: problemas e perspectivas. São Paulo: Paulus, 2008. p. 117-162.

GOMES, W. Internet e participação política. In: GOMES, W.; MAIA, R. Comunicação e democracia: problemas e perspectivas. São Paulo: Paulus, 2008. p. 293-325.

GOMES, Wilson. A democracia digital e o problema da participação civil na decisão política. Fronteiras-estudos midiáticos, São Leopoldo, v.7, n.3, p. 214-222, 2005.

GOMES, Wilson. A democracia digital e o problema da participação civil na decisão política. Fronteiras-estudos midiáticos, São Leopoldo, v.7, n.3, p. 214-222, 2005.

GOMES, Wilson. Participação política online: questões e hipóteses de trabalho. In: GOMES, W.; MAIA, R. C. M.; MARQUES, F. P. J. A. Internet e Participação Política no Brasil. Porto Alegre: Sulina, 2011. cap. 1, p. 19-35.

GRAHAM, T. Needles in a Haystack: a new approach for identifying and assessing politial talk in non-political discussion forums. In: Jav-Host - The Public. v. 15, n. 2, p. 1736, 2008.

HABERMAS, J. Direito e Democracia: entre facticidade e validade. v. I e II. Tradução de F. Siebeneichler. Rio de Janeiro: Tempo Brasileiro, 1997.

KIES, R. Promises and limits of Web-deliberation. Nova York: Palgrave Macmillan, 2010.

LIMA, Venício. Sobre a cultura do silêncio. 2017. Disponível em: <https://www.cartamaior.com.br/?/Editoria/Midia-e-Redes-Sociais/Sobre-acultura-do-silencio-1-/12/38974> Acesso em: 20 mar. 2019.

MAIA, R. C. M. Conversação Cotidiana e deliberação. In: GOMES, W.; MAIA, R. C. M. Comunicação e Democracia: problemas \& perspectivas. São Paulo: Paulus, 2008.

MARQUES, A. Aspectos teórico-metodológicos do processo comunicativo de deliberação online. In: Revista Brasileira de Ciência Política, Brasília, n. 6, p. 19-40, jul. /dez. 2011. 
MATOS, E; BARROS. S; CARREIRO, R. "Ouvindo nosso bairro": um estudo sobre a participação política local por meio de multiplataformas. in: Comunicação e política: interfaces em esferas regionais. São Luís: EDUFAMA, 2019. p. 203-227.

ROSSETTO, G. P. N.; CARREIRO, R.; REIS, L. Conversação Política no Facebook: um estudo sobre a crise da água no Brasil. In: Congresso o Compolítica, 16. Rio de Janeiro. Anais... Rio de Janeiro: PUC-Rio, 2015.

STROMER-GALLEY, Jennifer. Decoding deliberation online. In.: Second Conference on Online Deliberation, Palo Alto, California, Anais... California: Online Deliberation, mai. 2005. 


\section{Crevisto Observatório}

\section{ABSTRACT:}

The purpose of this article is to discuss the act of political participation by citizens mediated by communication technologies. It is an effort to understand the potential scenarios and paths for the promotion of citizen participation in the sphere of public power. The investigation took place through the observation of a specific space on Facebook: the Plantão da Cidade group, conceived in the municipality of Ouro Preto to enable political discussions. The proposed exam highlights the possibilities offered by the online environment to ensure the political participation of ordinary people in municipal management decisions and the mobilization of local community actions.

KEYWORDS: Citizenship. Deliberation. Facebook. Political participation. Social networks.

\section{RESUMEN:}

El propósito de este artículo es discutir la participación política de los ciudadanos mediada por las tecnologías de la comunicación. Buscamos comprender los escenarios posibles y los medios para la promoción de la participación ciudadana en el universo del poder público. La investigación ocurre a partir de la observación de un espacio específico en Facebook: el grupo Plantão da Cidade, creado en la ciudad de Ouro Preto para viabilizar discusiones de naturaleza política. El análisis propuesto destaca las posibilidades ofrecidas por el ambiente online para garantizar la participación política del ciudadano común en las decisiones de la gestión municipal y la movilización de acciones comunitarias locales.

PALABRAS-CLAVES:

Ciudadanía;

Deliberación; Facebook; Participación política; Redes sociales. 